\title{
Productivity of a coral reef using boundary layer and enclosure methods
}

\author{
W. R. McGillis, ${ }^{1}$ C. Langdon, ${ }^{2}$ B. Loose, ${ }^{3}$ K. K. Yates, ${ }^{4}$ and Jorge Corredor ${ }^{5}$ \\ Received 17 November 2010; revised 6 December 2010; accepted 22 December 2010; published 15 February 2011.
}

[1] The metabolism of Cayo Enrique Reef, Puerto Rico, was studied using in situ methods during March 2009. Benthic $\mathrm{O}_{2}$ fluxes were used to calculate net community production using both the boundary layer gradient and enclosure techniques. The boundary layer $\mathrm{O}_{2}$ gradient and the drag coefficients were used to calculate productivity ranging from -12.3 to $13.7 \mathrm{mmol} \mathrm{O}_{2} \mathrm{~m}^{-2} \mathrm{~h}^{-1}$. Productivity measurements from the enclosure method ranged from -11.0 to $12.9 \mathrm{mmol} \mathrm{O}_{2}$ $\mathrm{m}^{-2} \mathrm{~h}^{-1}$. During the study, the mean hourly difference between the methods was $0.65 \mathrm{mmol} \mathrm{O}_{2} \mathrm{~m}^{-2} \mathrm{~h}^{-1}\left(\mathrm{r}^{2}=0.92\right)$, resulting in well-reconciled estimates of net community production between the boundary layer $\left(-33.1 \mathrm{mmol} \mathrm{m}^{-2}\right.$ $\left.\mathrm{d}^{-1}\right)$ and enclosure $\left(-46.3 \mathrm{mmol} \mathrm{m} \mathrm{m}^{-2} \mathrm{~d}^{-1}\right)$ techniques. The results of these independent approaches corroborate quantified rates of metabolism at Cayo Enrique Reef. Close agreement between methods demonstrates that boundary layer measurements can provide near real-time assessments of coral reef health. Citation: McGillis, W. R., C. Langdon, B. Loose, K. K. Yates, and J. Corredor (2011), Productivity of a coral reef using boundary layer and enclosure methods, Geophys. Res. Lett., 38, L03611, doi:10.1029/2010GL046179.

\section{Introduction}

[2] Coral reefs are under increasing environmental stress from overfishing, sedimentation, pollution, eutrophication, warming and ocean acidification. Therefore, there is a pressing need to develop methods that can measure coral reef health under natural conditions. Measurement of the rates of photosynthesis and respiration are fundamental to the understanding of coral reef ecosystems. The balance between photosynthesis and respiration determines if the ecosystem is producing more organic matter than is required for daily maintenance and if the system is able to support some level of export production. Typically on a healthy reef, nutrient fluxes limit net ecosystem production in the range of $0-50 \mathrm{mmol} \mathrm{C} \mathrm{m} \mathrm{m}^{-2} \mathrm{~d}^{-1}$ [Atkinson and Falter, 2003]. Equally important is the net ecosystem rate of calcification and carbonate sediment accumulation. If this number is positive then the reef is accreting

\footnotetext{
${ }^{1}$ Lamont Doherty Earth Observatory, Earth Institute at Columbia University, Palisades, New York, USA.

${ }^{2}$ Rosenstiel School of Marine and Atmospheric Science, University of Miami, Miami, Florida, USA.

${ }^{3}$ Marine Chemistry and Geochemistry, Woods Hole Oceanographic Institution, Woods Hole, Massachusetts, USA.

${ }^{4}$ U.S. Geological Survey, St. Petersburg, Florida, USA.

${ }^{5}$ Department of Marine Sciences, University of Puerto Rico, Mayaguez, Puerto Rico.
}

Copyright 2011 by the American Geophysical Union. 0094-8276/11/2010GL046179 calcium carbonate. This means that corals and calcareous algae are producing $\mathrm{CaCO}_{3}$ faster than the physical and bioerosive processes are removing it, thus maintaining the reef integrity and capability to keep up with sea level rise.

[3] Historically, measurements of carbon cycling on coral reefs have been made employing the flow respirometry method whereby a parcel of water is tracked over a portion of reef and the changes in $\mathrm{O}_{2}$ or carbonate parameters are measured to determine the flux of carbon into and out of the organic matter and calcium carbonate pools [Marsh and Smith, 1978; Barnes, 1983; Griffith et al., 1987; Gattuso et al., 1993, 1996]. Variations of the method include Eulerian approaches [Frankignoulle et al., 1996] and slack water approaches [Kinsey, 1978]. These methods are labor intensive and are difficult to deploy in extended autonomous modes. It is necessary to repeat the measurements at different times of the day and night. Often it takes days to a week to accumulate enough data to compile a single diurnal response that could then be integrated to yield the desired 24-h cumulative rate of net community production (NCP) or calcification [Barnes and Devereux, 1984; Gattuso et al., 1993]. Further complication is introduced by having to measure over several hundred meters in order to accurately resolve the changes, making it difficult to obtain measurements over the same part of the reef from day to day.

\section{The Importance of Biogeochemical Measurements in Undisrupted Flow}

[4] There is growing recognition that transport of nutrients and other materials into and out of plant and sessile (animal consortia or consortium) organisms such as corals and benthic algae, is strongly affected by the local flow field surrounding the organism and therefore mass-transport limited [Atkinson and Bilger, 1992; Lesser et al., 1994; Baird and Atkinson, 1997; Yahel et al., 1998; Genin et al., 2002; Sebens et al., 2003; Yahel et al., 2005]. Thus, there is a need to implement methods for measuring metabolism in the ambient environment. Such methods would be an excellent complement to enclosure experiments that are capable of mass balance closure and serve as "in-situ laboratories" where ambient conditions can be varied and ecosystem responses measured. Two new methods have recently been shown to permit the continuous measurement of in-situ rates of $\mathrm{O}_{2}$ evolution and consumption of benthic communities without altering the flow. These are the control-volume method and the boundary layer method. These methods show promise of transforming the understanding of how photosynthesis and respiration rates of benthic communities vary in time and space and what factors control those rates. The boundary layer method has been recently applied to the benthic flux of phytoplankton by Jones et al. [2009]. 
[5] One innovative example of the control-volume approach was performed by Falter et al. [2008]. A triangular array of ADCPs and Aanderaa Optode $\mathrm{O}_{2}$ sensors were deployed on the Kaneohe Bay Barrier Reef, Hawaii. Continuous measurements of the rate of net $\mathrm{O}_{2}$ evolution were measured over an 18-d period in December 2006. Lagrangian measurements of $\mathrm{O}_{2}$ flux performed by following $\mathrm{O}_{2}$ changes in a dye patch as it drifted through the control volume were shown to be in good agreement with the control volume $\mathrm{O}_{2}$ fluxes. NCP averaged over the study period was $5 \pm 123 \mathrm{mmol}$ $\mathrm{O}_{2} \mathrm{~m}^{-2} \mathrm{~d}^{-1}$ and ranged from -200 to $190 \mathrm{mmol} \mathrm{O}_{2} \mathrm{~m}^{-2} \mathrm{~d}^{-1}$ indicating the extent of day-to-day variability that can be experienced and the need for a method that may perform over an extended period of time. While this method is clearly a major advancement, it has some limitations. The authors suggest that the minimum length scale to ensure a measurable horizontal gradient in $\mathrm{O}_{2}$ is approximately $250 \mathrm{~m}$ and that the maximum depth is on the order of $3-4 \mathrm{~m}$. The study duration is also limited by biofouling and drift in the $\mathrm{O}_{2}$ sensor.

[6] Boundary layer methods include the eddy-correlation or direct covariance (DC) flux method and the gradient flux (GF) method. These techniques are advancements that permit noninvasive measurements of benthic fluxes [Berg et al., 2003; Berg and Huettel, 2008]. The GF technique is an alternative boundary-layer method, which has been successfully applied to coral reefs to determine the momentum flux [Reidenbach et al., 2006]. However, chemical boundary layer flux measurements over corals have not been reported. Chemical boundary layer gradient flux techniques have been performed at the air-water surface [McGillis et al., 2001, 2007]. The gradients of carbon dioxide and dimethylsulfide in the atmosphere are small. To measure accurate gradients, the single detector differencing method was performed [McGillis et al., 2004].

[7] In this study, a boundary layer method capable of measuring coral metabolism with high spatiotemporal resolution is compared with the enclosure technique. While all enclosures impede natural water flow to some extent, more recent methods employ enclosures constructed of flexible structures and flow systems that provide water circulation and oscillatory water flow throughout the chamber [Yates and Halley, 2003; Carpenter et al., 1991]. A combination of boundary layer gradient and enclosure methods may be necessary to understand how individual parts of the reef are contributing to the whole under natural conditions and how they respond to short term physical and chemical forcing during perturbation experiments.

\section{Materials and Methods}

[8] Net production (np) of a shallow coral reef in La Parguera, Puerto Rico was measured using a boundary layer gradient flux method (Coral Reef Oxygen Sensing System, CROSS) and an enclosure method (Submersible Habitat for Analyzing Reef Quality, SHARQ). Results from each method are compared to demonstrate the efficacy of these approaches for monitoring metabolism as a proxy for reef health and for experimentation on community response to environmental perturbations.

\subsection{Study Site}

[9] The CROSS and SHARQ were deployed on the fore reef on the western end of Cayo Enrique (Enrique), a shelf reef located on the broad insular continental shelf on the SW coast of Puerto Rico approximately $1.6 \mathrm{~km}$ from the coast. The fore reef of Enrique is relatively broad at its eastern end sloping from a depth of 1 to $21 \mathrm{~m}$, and gets narrower and steeper moving westward [Morelock et al., 1977]. Natural disturbances including hurricane Georges, the die off of Diadema and mass bleaching events have significantly impacted the coral community here and throughout the Caribbean in recent decades. Belt transect surveys done at the time of the study showed that live coral cover in the area averaged $10 \%$. The scleractinian coral species observed comprised Siderastrea siderea, Porites astreoides, Diploria strigosa $S$. radians, $D$. clivosa, and $P$. porites ranked in order of areal cover. The predominant current in the area is directed towards the west, parallel to the axis of the reef at a speed of $2-10 \mathrm{~cm} \mathrm{~s}^{-1}$.

\subsection{The SHARQ Enclosure Method}

[10] SHARQ is a transparent bottom-mounted enclosure that isolates water above the coral [Yates and Halley, 2003]. The SHARQ was deployed at $5.2 \mathrm{~m}$ depth on the fore reef slope of Enrique near the CROSS (latitude $17^{\circ} 57.195^{\prime} \mathrm{N}$, longitude $67^{\circ} 02.878^{\prime} \mathrm{W}$ ) from March 21-27, 2009. Net community production was computed from changes in enclosure $\mathrm{O}_{2}$ inventory over time. Dissolved $\mathrm{O}_{2}$ (DO) was measured every minute during six 24-hour incubation periods using YSI model 52 dissolved $\mathrm{O}_{2}$ meters and pressure compensated field probes $( \pm 3.1 \mu \mathrm{mol} / \mathrm{kg})$. Seawater in the enclosure was periodically vented to the atmosphere using a gas equilibration chamber located in-line with the flowthrough analytical system to prevent depletion of $\mathrm{O}_{2}$ during dark periods of net respiration. The enclosure was opened for 16 hours between March 24 and 25 to replenish with ambient water and prevent depletion of nutrients. Net community production was calculated every $15 \mathrm{~min}$. by $\mathrm{dO}_{2} / \mathrm{dt}$ $\mathrm{V} / \mathrm{SA}$, whereby $\mathrm{dO}_{2} / \mathrm{dt}$ is the time rate of change of $\mathrm{O}_{2}$ concentration in the enclosure $\left(\mathrm{mmol} \mathrm{m}^{-3}\right), \mathrm{V}$ is the volume of the SHARQ, and SA is the benthic surface area covered by the enclosure. Measured quantities of fluorescein dye were injected into the enclosure and measured continuously as a proxy for leaks. No corrections for $\mathrm{O}_{2}$ exchange with water outside of the chamber were required.

\subsection{The CROSS Chemical Boundary Layer Method}

[11] CROSS is designed to make unobstructed measurements of vertical gradients in velocity, temperature, and chemical constituents to calculate the flux of momentum, heat, and $\mathrm{O}_{2}$ in the boundary layer. The CROSS was deployed on Enrique, approximately $500 \mathrm{~m}$ to the west of the SHARQ enclosure at the same depth, during March 24-29, 2009. The CROSS was positioned to be far enough way from the SHARQ to avoid possible flow disturbances, while experiencing the same ambient conditions, including depth, radiation and coral community structures.

[12] The CROSS system is currently an integration of an Acoustic Doppler Velocimeter (ADV), a Modular Acoustic Velocity Sensor (MAVS) and two Aanderaa Optode $\mathrm{O}_{2}$ sensors. The $\mathrm{O}_{2}$ and current sensors were positioned at $0.2 \mathrm{~m}$ and $0.9 \mathrm{~m}$ above the reef floor on a PVC stand. The dissolved $\mathrm{O}_{2}$ sensors were calibrated against discrete $\mathrm{O}_{2}$ samples analyzed by Winkler titration using an automated amperometric titrator [Culberson and Huang, 1987]. The typical precision of the method is $\pm 0.15 \mu \mathrm{mol} / \mathrm{kg}$. 

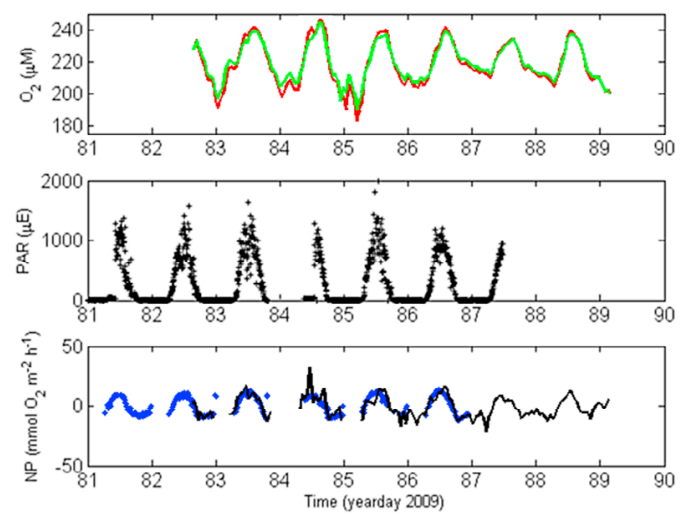

Figure 1. Time series of data from Enrique Reef in La Parguera, Puerto Rico collected using the boundary layer flux method (CROSS) and the enclosure method (SHARQ) during March 2009. (top) Simultaneous dissolved $\mathrm{O}_{2}$ time series measurements at $0.2 \mathrm{~m}$ (red line) and at $0.9 \mathrm{~m}$ (green line) are shown. Data show periods of net $\mathrm{O}_{2}$ production (photosynthesis) at mid day and net $\mathrm{O}_{2}$ consumption (respiration) at night. DO is measured every minute and data shown are hourly averages. (middle) Incident PAR measurements located on the seafloor next to the SHARQ system are shown during the deployment. (bottom) $\mathrm{Net}_{2} \mathrm{O}_{2}$ production measured with the CROSS (black) using the simultaneous gradients in $\mathrm{O}_{2}$ and velocity and the SHARQ (blue) performing conservative mass balances in the enclosure.

[13] Net productivity from the GF method can be formulated as the product of the eddy diffusivity, $K_{z}$, times the vertical concentration gradient in $\mathrm{O}_{2}(\mathrm{~d} D O / \mathrm{dz}) . K_{z}$ can be expressed as $K_{z}=u_{*} \kappa z$, so that $n p$ is:

$$
n p=\rho u_{*} \kappa \frac{\left(D O_{z=2}-D O_{z=1}\right)}{\ln \left(z_{2} / z_{1}\right)}
$$

where $\rho$ is the density of the seawater $\left(\mathrm{kg} \mathrm{m}^{-3}\right), u_{*}$ is the friction velocity, $\kappa$ is the Kármán constant, $D O_{z}$ is the dissolved $\mathrm{O}_{2}$ concentration $\left(\mathrm{mmol} \mathrm{kg}{ }^{-1}\right)$ at 0.2 or $0.9 \mathrm{~m}$ above the seafloor. The friction velocity, $u_{*}$, also derives from the boundary layer theory on the same time and spatial scale as the chemical constituents. For a neutral boundary layer, $u_{*}=\kappa \frac{d U}{d \ln z}=\kappa \frac{\left(U_{z=2}-U_{z=1}\right)}{\ln \left(z_{2} / z_{1}\right)}$, which was solved sequentially for every instantaneous value of $U$ resulting from the MAVS and ADV sensors at their respective heights to obtain the ensemble. Aanderaa $\mathrm{O}_{2}$ optodes were sampled at a rate of once per minute. Just before deployment the sensors were placed immediately adjacent to each other and a discrete $\mathrm{O}_{2}$ sample was collected and titrated by Winkler titration. This was done to remove any small difference that might exist between the two sensors. Hourly averages of $u_{*}$ and $\mathrm{O}_{2}$ concentration were obtained and from these the hourly rates of $n p$ were computed using equation (1). The footprint or region of influence over which the boundary layer calculation is applicable can be developed from the conservation of mass as, $u_{*} / z=U_{o} / L$, where $\mathrm{L}$ is the footprint length and $\mathrm{z}$ corresponds to the measurement height. A LiCor $4 \prod$ PAR (photosynthetically active radiation) sensor was placed approximately $10 \mathrm{~cm}$ from the seafloor near the SHARQ chamber at a depth of $5.2 \mathrm{~m}$.

\section{Results and Discussion}

[14] Figure 1 shows the hourly-averaged data from an 8-day CROSS deployment in March 2009 on Enrique. The concentration of $\mathrm{O}_{2}$ varies from day to night due to photosynthesis and respiration. The concentration difference between the $\mathrm{O}_{2}$ sensors changes during the day and the sign of the gradient shifts between day and night reflecting $\mathrm{O}_{2}$ production at the seafloor surface during the mid-day and $\mathrm{O}_{2}$ consumption at night. This diurnal cycle matches incident PAR measurements (shown in Figure 1). Figure 1 also shows the time series of both the SHARQ and CROSS hourly net production (np). The np time series shows that the $\mathrm{O}_{2}$ fluxes computed by the CROSS boundary layer GF method are in good agreement with the rates determined by the SHARQ. Data gaps in the SHARQ time series correspond to times when the enclosure is replenished with ambient water or when enclosure water is vented to the atmosphere. Gaps in the CROSS data occur when the tidal flow is near slack or causes the boundary layer to flow over the instrumentation and disrupts the criteria for boundary layer flow. The mean $\frac{u_{*}}{U_{o}}$ from the GF method was $0.14 \pm .01$, which was slightly higher than the 0.10-0.12 measured by Reidenbach et al. [2006] over a Red Sea fringing reef. $U_{0}$ is the bulk mean water speed. This water current velocity is the mean velocity to characterize the flow. The velocity is used as the variable to define the drag coefficient. This corresponds to a drag coefficient, $\mathrm{C}_{\mathrm{d}}$ of $0.019 \pm 0.002$ where $C d=\left(\frac{u_{*}}{U_{o}}\right)^{2}$, and the footprint, $\mathrm{L}$ was approximately $6 \mathrm{~m}$, using $\mathrm{z}=0.9 \mathrm{~m}$.

[15] Rates of np are variable from day to day. On nearby San Cristobal reef, Rogers [1979] measured np as high as $13 \mathrm{mmol} \mathrm{m}^{-2} \mathrm{~h}^{-1}$ using a flow through enclosure. These are in general agreement with the high rates measured with the CROSS and SHARQ in this study. Rogers [1979] did not measure nighttime np but simulated dark respiration by performing measurements with opaque reef covers. The np measurements of this study are similar, but slightly less than the values reported by Falter et al. [2008]. Those measurements were based on their modified Eulerian approach where lateral cross-reef and along-reef advective $\mathrm{O}_{2}$ fluxes were needed to be quantified on the boundaries of a control volume. Figure 2 shows the diel average of the incident seafloor PAR, CROSS np, and SHARQ np for Enrique.

[16] The gross primary production (GPP), 24-hour respiration (R), and NCP were calculated for the averaged diurnal cycle. The CROSS (-33.1 NCP, $-206.5 \mathrm{R}, 173.4 \mathrm{GPP})$ and SHARQ (-46.3 NCP, $-168.5 \mathrm{R}, 122.1 \mathrm{GPP})$ are in fairly good agreement. These rates are lower than the results from the Eulerian Method ( -65 NP, -465 R, 400 GPP) from Falter et al. [2008] on the Kaneohe Bay Barrier Reef, Hawaii, possibly indicating differences in biota or reef health between the two sites. These findings suggest that continuous $\mathrm{np}$ measurements can be performed for durations sufficient to obtain a useful average necessary to determine long-term reef metabolism.

[17] As shown in Figure 2, PAR is the predominantly environmental factor controlling CROSS and SHARQ np. Daytime productivity is linked directly to the incident solar 


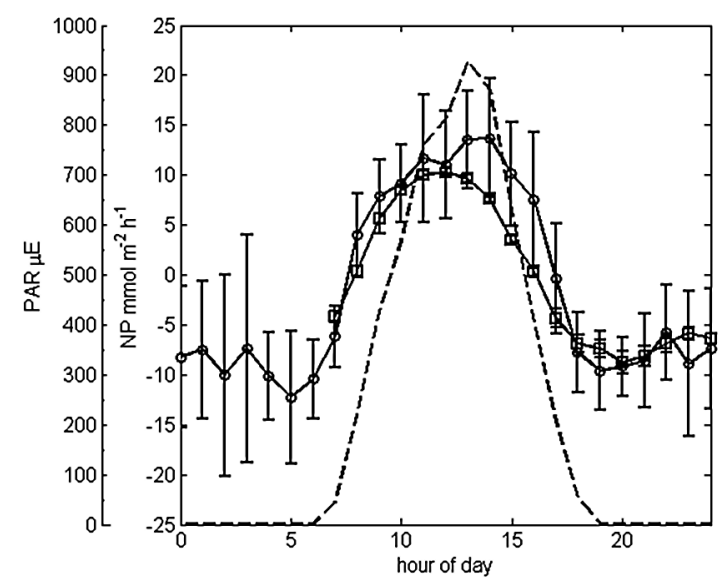

Figure 2. Average diurnal net $\mathrm{O}_{2}$ production from the March 2009 deployment. PAR (dashed-line), CROSS (circles), and SHARQ (squares) are shown for comparison. Vertical bars are the standard deviation. The productivity is light sensitive. Continuous overlap did not exist for CROSS and SHARQ measurements. Over the 8-day period, the diurnal NCP data are in very good agreement.

radiation. Some of the correlations in the trends are within the uncertainty and variability of the measurements. While within the standard deviations of the ensemble diurnal data, it is worth noting that the same small variability in the peak incident PAR is seen in a peak in the average CROSS np response. CROSS np is slightly higher than SHARQ np. The mean standard deviation of the SHARQ was $0.64 \mathrm{mmol} \mathrm{m}^{-2}$ $\mathrm{h}^{-1}$ while the CROSS was $5.6 \mathrm{mmol} \mathrm{m}^{-2} \mathrm{~h}^{-1}$. This difference may be a result of nutrient depletion within the closed environment of the SHARQ system, but may also result from slight variations in respiration rate at the two locations. The CROSS is an open system and is not subject to any influence in nutrient depletion.

\section{Conclusions}

[18] The GF method provides a means for continuously monitoring the overall metabolic activity of the reef community in undisturbed flow conditions with high spatial $(10 \mathrm{~m})$ and temporal resolution (minutes). Results demonstrate the value of an integrated approach combining interdisciplinary capabilities from the fields of physics, biogeochemistry, and methodology for improved and cost-effective measurements of community metabolism in coastal ecosystems. The method can be employed at any depth because it is dependent only on the gradient in the boundary layer and not a signal integrated over the overlying water column. The method can be adapted to estimate the flux of constituents for which an accurate in situ sensor does not exist, but for which the BL gradient can be characterized based on discrete measurements. For example, we have found that a measureable alkalinity gradient can be discernible in the BL over a coral reef and that calcification rates can be obtained. Given the small footprint of the method it is possible to investigate the impact of bleaching, disease and other disturbances that impact a group of coral colonies in one area but not in a nearby area. The physicochemical conditions in the ocean that have favored extensive reef development throughout the tropics and have been fairly stable for the last 5000 years are starting to deteriorate at an alarming rate. Thus, the GF method may be valuable in studies investigating the impacts of climate change, global warming, nutrient availability, and ocean acidification on coral reef health where there will be a need for methods that can be employed at many remote locations to determine whether trends in coral reef metabolism are global in scope and temporally coherent with observed changes in climate and ocean chemistry.

[19] Acknowledgments. The authors are grateful to the NOAA CORAL REEF Watch Program and the University of Puerto Rico Marine Laboratory. We would like to thank Jon Ware (WHOI) for the fabrication of CROSS. We would also like to extend our gratitude to Luis Soler-López and Pedro Díaz of the USGS in San Juan, Puerto Rico; Nathan Smiley and Chris Dufore of the USGS in St. Petersburg, Florida; and John MacAllister, Carol MacAllister, and Ismael Ramos-Soler for their support and assistance with field deployments and logistics.

\section{References}

Atkinson, M. J., and R. W. Bilger (1992), Effects of water velocity on P uptake in coral reef flat communities, Limnol. Oceanogr., 37, 273-279, doi:10.4319/lo.1992.37.2.0273

Atkinson, M. J., and J. Falter (2003), Biogeochemistry of coral reefs, in Biogeochemistry of Marine Ecosystems, edited by K. Black and G. Shimmield, pp. 40-64, CRC Press, Boca Raton, Fla.

Atkinson, M. J., and R. W. Grigg (1984), Model of a coral reef ecosystem. II. Gross and net benthic primary production at French Frigate Shoals, Coral Reefs, 3, 13-22, doi:10.1007/BF00306136.

Baird, M., and M. J. Atkinson (1997), Measurement and prediction of mass transfer to coral reefs, Limnol. Oceanogr., 42, 1685-1693, doi:10.4319/ lo.1997.42.8.1685.

Barnes, D. J. (1983), Profiling coral reef productivity and calcification using pH and oxygen electrodes, J. Exp. Mar. Biol. Ecol., 66, 149-161, doi:10.1016/0022-0981(83)90036-9.

Barnes, D. J., and M. J. Devereux (1984), Productivity and calcification on a coral reef: A survey using $\mathrm{pH}$ and oxygen electrode techniques, J. Exp. Mar. Biol. Eco., 79(3), 213-231, doi:10.1016/0022-0981(84)90196-5.

Berg, P., and M. Huettel (2008), Monitoring the seafloor using the noninvasive eddy correlation technique: Integrated benthic exchange dynamics, Oceanography, 21, 164-167.

Berg, P., H. Roy, F. Janssen, V. Meyer, B. P. Jorgensen, M. Huettel, and D. de Beer (2003), Oxygen uptake by aquatic sediments measured with a novel non-invasive eddy-correlation technique, Mar. Ecol. Prog. Ser., 261, 75-83, doi:10.3354/meps261075.

Carpenter, R. C., J. M. Hackney, and W. Adey (1991), Measurements of primary productivity and nitrogenase activity of coral reef algae in a chamber incorporating oscillatory flow, Limnol. Oceanogr., 36, 40-49, doi:10.4319/lo.1991.36.1.0040.

Culberson, C. H., and S. Huang (1987), Automated amperometric oxygen titration, Deep Sea Res., Part A, 34, 875-880, doi:10.1016/01980149(87)90042-2.

Falter, J. L., R. J. Lowe, M. J. Atkinson, and S. G. Monismith (2008), Continuous measurements of net production over a shallow reef community using a modified Eulerian approach, J. Geophys. Res., 113, C07035, doi:10.1029/2007JC004663.

Frankignoulle, M., J.-P. Gattuso, R. Biondo, I. Bourge, G. Copin-Montégut, and M. Pichon (1996), Carbon fluxes in coral reefs. II. Eulerian study of inorganic carbon dynamics and measurement of air-sea $\mathrm{CO}_{2}$ exchanges, Mar. Ecol. Prog. Ser., 145, 123-132, doi:10.3354/meps145123.

Gattuso, J.-P., M. Pichon, B. Delesalle, and M. Frankignoulle (1993), Community metabolism and air-sea $\mathrm{CO}_{2}$ fluxes in a coral reef ecosystem (Moorea, French Polynesia), Mar. Ecol. Prog. Ser., 96, 259-267, doi:10.3354/meps096259.

Gattuso, J.-P., M. Pichon, B. Delesalle, C. Canon, and M. Frankignoulle (1996), Carbon-fluxes in coral reefs. I. Lagrangian measurement of community metabolism and resulting air-sea $\mathrm{CO}_{2}$ disequilibrium, Mar. Ecol. Prog. Ser., 145, 109-121, doi:10.3354/meps145109.

Genin, A. G., M. A. Yahel, M. Reidenbach, J. R. Koseff, and S. G. Monismith (2002), Intense benthic grazing on phytoplankton in coral reefs revealed using the control volume approach, Oceanography, 15, 90-96.

Griffith, P. C., J. D. Cubit, W. H. Adey, and J. N. Norris (1987), Computerautomated flow respirometry: Metabolism measurements on a Caribbean reef flat and in a microcosm, Limnol. Oceanogr., 32, 442-451, doi:10.4319/lo.1987.32.2.0442. 
Jones, N. L., J. K. Thompson, K. R. Arrigo, and S. G. Monismith (2009), Hydrodynamic control of phytoplankton loss to the benthos in an estuarine environment, Limnol. Oceanogr., 54, 952-969.

Kinsey, D. W. (1978), Productivity and calcification estimates using slackwater periods and field enclosures, in Coral Reefs: Research Methods, edited by D. R. Stoddart and R. E. Johannes, pp. 439-468, UNESCO, Paris.

Lesser, M. P., V. M. Weis, M. R. Patterson, and P. L. Jokiel (1994), Effects of morphology and water motion on carbon delivery and productivity in the reef coral, Pocillopora damicornis (Linnaeus): Diffusion barriers, inorganic carbon limitation, and biochemical plasticity, J. Exp. Mar. Biol. Ecol., 178, 153-179, doi:10.1016/0022-0981(94)90034-5.

Marsh, J. A., and S. Smith (1978), Productivity measurements of coral reefs in flowing waters, in Coral Reefs: Research Methods, edited by D. R. Stoddart and R. E. Johannes, pp. 361-378, UNESCO, Paris.

McGillis, W. R., J. B. Edson, J. D. Ware, J. W. H. Dacey, J. E. Hare, C. W. Fairall, and R. Wanninkhof (2001), Carbon dioxide flux techniques performed during GasEx-98, Mar. Chem., 75, 267-280, doi:10.1016/ S0304-4203(01)00042-1.

McGillis, W. R., et al. (2004), Air-sea $\mathrm{CO}_{2}$ fluxes in the equatorial Pacific, J. Geophys. Res., 109, C08S02, doi:10.1029/2003JC002256.

McGillis, W. R., J. W. H. Dacey, J. D. Ware, D. T. Ho, J. T. Bent, W. E. Asher, R. Wanninkhof, and S. Komori (2007), Air-water flux reconciliation between the atmospheric $\mathrm{CO}_{2}$ profile and mass balance techniques, in Transport at the Air-Sea Interface, edited by C. S. Garbe, R. A. Handler, and B. Jahne, pp. 179-190, Springer, Berlin.

Morelock, J., N. Schniedermann, and W. R. Bryant (1977), Shelf reefs, southwestern Puerto Rico, in Reefs and Related Carbonates-Ecology and Sedimentology, AAPG Stud. Geol., 4, 135-153.

Reidenbach, M., S. G. Monismith, J. R. Koseff, G. Yahel, and A. G. Genin (2006), Boundary layer turbulence and flow structure over a fringing coral reef, Limnol. Oceanogr., 51, 1956-1968, doi:10.4319/1o.2006. 51.5.1956.

Rogers, C. S. (1979), The productivity of San Cristobal Reef, Puerto Rico, Limnol. Oceanogr., 24, 342-349, doi:10.4319/lo.1979.24.2.0342.

Sebens, K. P., B. Helmuth, E. Carrington, and B. Agius (2003), Effects of water flow on growth and energetics of the scleractinian coral Agaricia tenuifolia in Belize, Coral Reefs, 22, 35-47.

Yahel, G., A. F. Post, K. E. Fabricius, D. Marie, D. Vaulot, and A. G. Genin (1998), Phytoplankton distribution and grazing near coral reefs, Limnol. Oceanogr., 43, 551-563, doi:10.4319/lo.1998.43.4.0551.

Yahel, R., G. Yahel, and A. G. Genin (2005), Near bottom depletion of zooplankton over coral reefs: I: Diurnal dynamics and size distribution, Coral Reefs, 24, 75-85, doi:10.1007/s00338-004-0449-z.

Yates, K. K., and R. B. Halley (2003), Measuring coral reef community metabolism using new benthic chamber technology, Coral Reefs, 22, 247-255, doi:10.1007/s00338-003-0314-5.

J. Corredor, Department of Marine Sciences, University of Puerto Rico, Mayaguez, PR 00681.

C. Langdon, Rosenstiel School of Marine and Atmospheric Science, University of Miami, 4600 Rickenbacker Cswy., Miami, FL 33149, USA.

B. Loose, Marine Chemistry and Geochemistry, Woods Hole Oceanographic Institution, 266 Woods Hole Rd., Woods Hole, MA 02543, USA.

W. R. McGillis, Lamont Doherty Earth Observatory, Earth Institute at Columbia University, 61 Rte. 9W, Palisades, NY 10964, USA. (wrm2102@columbia.edu)

K. K. Yates, U.S. Geological Survey, St. Petersburg, FL 33701, USA. 